\title{
Índice de produção ponderado de atividades de bibliotecas: uma abordagem multicriterial
}

\author{
Eliane Gomes \\ Graduada em engenharia química (UFRJ), com mestrado \\ e doutorado em engenharia de produção. \\ E-mail: eliane.gomes@embrapa.br \\ Maria de Cléofas Alencar \\ Graduada em biblioteconomia (FESPSP), com \\ mestrado em biblioteconomia (Kent State University) e \\ doutorado em psicologia educacional (Unicamp). \\ E-mail:cleo@cnpm.embrapa.br
}

\begin{abstract}
Resumo
Este artigo tem como objetivo propor um índice de produção ponderado de atividades de bibliotecas. O índice é composto dos diversos tipos de processos e serviços realizados pelas bibliotecas, e para agregá-los foram utilizados pesos gerados a partir dos julgamentos de valor de um bibliotecário sobre a importância relativa entre essas atividades. Para transformar os julgamentos qualitativos em quantitativos, foi usado o método multicritério Macbeth. A abordagem proposta, após discussão com diversos decisores, pode servir como medida de comparação entre bibliotecas, em especial quando estão sujeitas a uma administração central.
\end{abstract}

Palavras-chave

Atividades de biblioteca; Indicadores; Multicritério.

\section{Libraries activities weighted production indicator: a multicriteria approach}

\begin{abstract}
In this paper we propose a weighted production indicator to evaluate libraries activities. This indicator is composed by the various kinds of processes and services done in the libraries. In order to aggregate these processes and services, we used the weights obtained from a librarian value judgements about their relative importance. To transform qualitative judgements into quantitative ones, we used the Macbteh multicriteria method. The proposed approach, after discussions with other decison-makers, can be used as a comparative evaluation score, particularly when libraries are subjected to a central administration.
\end{abstract}

Keywords

Library activities; Indicators; Multicriteria.

\section{INTRODUÇÃO}

Desde o século XIX, o objetivo principal das bibliotecas é proporcionar aos seus usuários um serviço: o do acesso à informação. Atualmente, a diferença está nos canais adicionais e distintos pelos quais se oferece o serviço de biblioteca, e o desafio está em determinar como, quando e se esses meios deveriam ser usados. Por isso, as bibliotecas têm enfrentado sérios problemas com a aquisição, o armazenamento, o manuseio de documentos e seus registros, já que, quando se trata de mudanças tecnológicas, os efeitos e conseqüências são ainda mais significativos para esses procedimentos.

Buckland (1992) iniciou uma trajetória para redesenhar os serviços de bibliotecas, pressupondo que existe insuficiente atenção para planejamento estratégico de três a dez anos, atenção desproporcional às novas tecnologias da informação e considerável experiência para fundamentar-se um planejamento estratégico em bibliotecas. Como possível solução, o autor sugere bases gerais de planejamento e/ou uma estrutura geral para repensar os serviços de biblioteca do futuro e, dessa forma, preparar-se para retratar os primeiros princípios.

Uma análise comparada entre artigos de periódicos publicados na revista Ciência da Informação e no Library and Information Science Abstracts (Lisa) entre 1990 e 1999 mostra que 44,4\% dos artigos publicados no Brasil, ante $86,1 \%$ dos artigos nesse abstract internacional, são de temas relacionados aos seguintes serviços de bibliotecas: organização e gerência de atividades, serviços técnicos, entradas, tratamento, armazenamento, recuperação e disseminação de informação (MUELLER; PECEGUEIRO, 2001). Uma das razões para a concentração de artigos publicados sobre o tema "serviços de bibliotecas" pode ser atribuída à preocupação e à tentativa de acompanhamento do crescimento do setor de serviços na economia mundial pela comunidade acadêmica e de profissionais da área de biblioteconomia e ciência da informação. A busca de melhoria da qualidade está particularmente localizada na gestão de serviços.

O termo serviço encontrado na literatura serve para designar fenômenos com significados diferentes e com um bem comum - os benefícios para os clientes (SANTOS;FACHIN; VARVAKIS, 2003). No que se refere às características que os serviços possuem, a 
mais importante parece ser a participação do cliente no processo de produção do serviço, ressaltando-se a importância da gestão dos serviços. No caso dos serviços de biblioteca, além de a informação ser considerada um dos ativos organizacionais, os clientes de hoje são bem mais exigentes.

Buckland (1999) avançou na estrutura conceitual para os serviços de bibliotecas. Dividido em quatro partes, esse documento traz uma introdução com plano, origens e motivação, escopo, serviços de bibliotecas e seus usuários (considerados como um sistema) e definição teórica que identifica unicidade e característica desses serviços. Analisa também todos os serviços, as conexões e extensões e a reconsideração de determinados problemas a eles relativos. Uma das conclusões mais relevantes do trabalho é a de que a alocação dos recursos deverá determinar o perfil dos serviços oferecidos em bibliotecas, em termos de quantos ou quais títulos são adquiridos, quantos ou quais títulos são descartados, do regulamento para acesso e uso, acesso livre, duplicação, empréstimo etc., disponibilidade de espaço e de seu uso, tipo de arranjo físico, serviços de catálogos e de recuperação de informação e serviços de aconselhamento e de referência. Conseqüentemente, um sistema gerencial e político que envolve qualidade e valor agregados.

Nesse contexto, avaliar as atividades realizadas pelas bibliotecas tornou-se uma questão relevante, em especial porque elas têm importância diferenciada. Se essas atividades são feitas por bibliotecas de um sistema, como é o caso do Sistema de Bibliotecas da Empresa Brasileira de Pesquisa Agropecuária (Embrapa), que conta hoje com 38 unidades centrais e descentralizadas, essa avaliação torna-se ainda mais significativa, em especial para a gestão feita pela administração central.

Para os sistemas de gestão da qualidade total, indicadores de desempenho são ferramentas imprescindíveis de gestão, pois trazem valores de referência a partir dos quais se pode estabelecer uma comparação entre as metas planejadas e o desempenho adquirido. Esses indicadores podem ser as entradas em relação aos recursos essenciais para se oferecer um serviço, os processos ou atividades (como o recurso é utilizado) e os indicadores de serviços resultantes do uso desses recursos e o seu impacto, o efeito dessas saídas sobre outras variáveis ou fatores (STUBBS, 2004).

Este artigo tem como objetivo propor uma metodologia para a construção de um índice de produção de atividades realizadas pelas bibliotecas. Como cada ação realizada tem importância diferenciada, este é um índice ponderado em que cada peso tenta expressar a importância relativa de cada uma na composição da "ação global". O índice é composto dos diversos tipos de atividades realizadas pelas bibliotecas, e para agregá-las foram utilizados os julgamentos de valor da bibliotecária de uma das unidades descentralizadas da Embrapa. Para transformar os julgamentos de valor qualitativos em quantitativos, foi usado o método multicritério Macbeth (COSTA; VANSNICK, 1995, 1997; COSTA; CHAGAS, 2004).

Destaca-se que, como o artigo traz uma primeira proposta de como abordar o problema, foram considerados apenas os julgamentos de valor de um único decisor. Pode-se julgar que este procedimento seja inadequado, ao argumentar-se que os resultados teriam melhor sustentação se baseados em opiniões de múltiplos decisores ou por um processo de questionários. Entretanto, nesta primeira abordagem, optou-se pela opinião de um único decisor que refletiu intensamente e que conhecia bastante o assunto, em vez de usar a opinião de diversos peritos que poderiam emitir julgamentos superficiais, já que os resultados aqui apresentados não pretendem ser definitivos e podem ser entendidos como os de um estudo-piloto.

Dessa forma, para que o índice proposto possa servir como medida de comparação entre diversas bibliotecas sujeitas a uma administração central, ele deve ser validado, considerando-se os julgamentos de outros decisores envolvidos no processo.

Cabe ainda ressaltar que o termo atividade será aqui usado para designar genericamente todos os processos e serviços realizados na biblioteca, sejam relacionados diretamente ao atendimento do cliente, ou referentes às ações internas (por exemplo, organização e processamento).

\section{MATERIAL E MÉTODO}

\section{APOIO MULTICRITÉRIO À DECISÃo}

O apoio multicritério à decisão (AMD) consiste em um conjunto de métodos e técnicas para auxiliar ou apoiar pessoas e organizações a tomar decisões, quando da presença de uma multiplicidade de critérios (GOMES; ALMEIDA, 2002). A aplicação de qualquer método de análise multicritério pressupõe a especificação do objetivo que o decisor pretende alcançar, quando deseja comparar entre si alternativas de decisão recorrendo ao uso de múltiplos critérios.

No AMD, buscam-se construir modelos que legitimem os juízos de valor subjetivos, ou seja, pressupõe aceitar que a subjetividade estará presente em todo o processo de decisão. Dessa forma, a estrutura de valores dos decisores é associada aos critérios existentes, que serão usados na avaliação das alternativas (YU, 1985). 
A análise de decisão com múltiplos critérios é um processo iterativo, mas pode ser apresentado como a seqüência das seguintes etapas (Gomes; Gonzalez-Araya; Carignano, 2004): 1) identificação dos decisores e seus objetivos; 2) definição das alternativas; 3) definição dos critérios relevantes para o problema de decisão; 4) avaliação das alternativas em relação aos critérios; 5) determinação da importância relativa dos critérios; 6) realização da avaliação global de cada alternativa; 7) análise de sensibilidade; 8) recomendação; 9) implementação.

As etapas 1, 2 e 3 são conhecidas como fase de estruturação do problema, a qual, segundo Costa , Ferreira e Correa (2000), representa cerca de $80 \%$ do total do problema. Esta fase trata da formulação do problema e busca identificar, caracterizar e organizar os fatores considerados relevantes no processo de apoio à decisão. É uma fase interativa e dinâmica, pois fornece uma linguagem comum aos decisores, o que possibilita a aprendizagem e o debate.

As etapas 4, 5, 6 e 7 compõem a fase de avaliação, que tem como objetivo a aplicação de métodos de análise multicritério para apoiar a modelagem das preferências e a sua agregação. A terceira fase, composta das etapas 8 e 9, é a fase de recomendação dos cursos de ação a serem seguidos.

Em relação à etapa 3, cabe ressaltar que, em um problema de decisão complexo, os critérios podem ser estruturados na forma de hierarquia ou árvore, na qual o nível do critério mais elevado é decomposto em níveis mais detalhados (GOMES; GONZALEZ-ARAYA; CARIGNANO, 2004).

Deve-se ainda atentar que uma família de critérios, ou seja, o conjunto de critérios utilizados em determinada situação de decisão, deve satisfazer a três condições (axiomas de Roy) para que seja uma família coerente de critérios (ROY; BOUYSSOU, 1993; MELLO et alii, 2003): exaustividade (impõe a necessidade de descrever o problema levando em conta todos os aspectos relevantes); coesão (obriga a correta análise de quais são os critérios de maximização e quais os de minimização); não-redundância (obriga a excluir critérios que estejam avaliando características já avaliadas por outro critério).

Em AMD, os juízos de valor dos decisores são expressos por meio de suas estruturas de preferência entre pares de alternativas ou critérios. As quatro relações fundamentais são indiferença, preferência estrita, preferência fraca e incomparabilidade (ROY; BOUYSSOU, 1993; DIAS, ALMEIDA; CLÍMACO, 1996).

A forma de explicitar as estruturas de preferência do decisor varia de acordo com o método de análise multicritério escolhido. Para a construção do índice de produção das bibliotecas, foi escolhido um método da escola americana de multicritério (GOMES;, GONZALEZARAYA, CARIGNANO, 2004; POMEROL; BARBAROMERO, 2000; GOMES, 1999), já que o objetivo é construir um índice único que agrega, por meio de pesos (também chamados de constantes de escala ou taxas de substituição), as diversas atividades realizadas pela biblioteca da Embrapa Monitoramento por Satélite. O método escolhido é o (Measuring Attractiveness by a Categorical Based Evaluation Technique) Macbeth.

\section{MACBETH}

O método Macbeth, desenvolvido por Costa e Vansnick (1995, 1997) e apresentado em Costa e Chagas (2004) e Costa, Ferreira e Correa (2000), permite agregar os diversos critérios de avaliação em um critério único de síntese, por meio da atribuição de pesos aos vários critérios, respeitando as opiniões dos decisores.

Mediante a comparação par a par da atratividade das alternativas, são atribuídos os pesos aos critérios: dadas duas alternativas, o decisor deve dizer qual a mais atrativa (deve receber a maior nota) e qual o grau desta atratividade em uma escala semântica que tem correspondência com uma escala ordinal ( $0 \equiv$ indiferente, $1 \equiv$ diferença de atratividade muito fraca, $2 \equiv$ diferença de atratividade fraca, $3 \equiv$ diferença de atratividade moderada, 4 = diferença de atratividade forte, $5 \equiv$ diferença de atratividade muito forte e $6 \equiv$ diferença de atratividade extrema).

O software que implementa computacionalmente o método faz a análise de coerência dos julgamentos e sugere, em caso de incoerência, como resolvê-la. Por programação linear, é sugerida uma escala de notas e os intervalos em que elas podem variar sem tornar o problema inconsistente (problema de programação linear inviável). É ainda facultado ao decisor ajustar graficamente o valor das notas atribuídas, dentro dos intervalos permitidos (análise de sensibilidade). Segundo Costa e Vansnick (1997), somente após este ajuste, com a introdução do conhecimento do especialista, é que fica caracterizada a construção da escala cardinal (quantitativa) de valores.

Matematicamente, a metodologia Macbeth é constituída por quatro problemas de programação linear (PPLs) seqüenciais:

- PPL 1 - Problema Mc1: realiza a análise de consistência cardinal;

- PPL 2 - Problema Mc2: responsável pela construção da escala de valor cardinal; 
- PPLs 3 e 4 - Problemas Mc3 e Mc4: revelam fontes de inconsistência.

Para operacionalizar o método, Costa e Vansnick (1995) propõem a construção de matrizes de juízos de valor, a fim de facilitar a expressão dos julgamentos absolutos de diferença de atratividade entre os pares de ações. Cada elemento xij da matriz toma o valor $k(k=1,2,3,4,5,6)$, se o decisor julgar que a diferença de atratividade do par $(a i, a j)$ pertence à categoria $C k$. Estes números não têm significado matemático, servem apenas como indicadores semânticos de qual categoria de diferença de atratividade foi atribuída ao par respectivo.

Com este conjunto de julgamentos, a metodologia Macbeth é executada, primeiramente, para a verificar eventuais inconsistências e, posteriormente, para determinar uma escala de valor cardinal que represente os julgamentos de valor do decisor. A escala obtida é normalizada, fornecendo os valores dos pesos para as alternativas em avaliação, o que possibilita o uso de um modelo de agregação, em geral, aditivo.

\section{MODELAGEM}

Como observado anteriormente, a primeira fase de uma modelagem multicritério é a fase de estruturação, composta de três etapas. Na primeira etapa, foram identificados os decisores e seus objetivos. $\mathrm{O}$ agente decisor foi a bibliotecária da Embrapa Monitoramento por Satélite, isto é, foi quem elegeu as ações a avaliar e emitiu os juízos de valor acerca das diferenças de atratividade entre as ações.

O objetivo do decisor é gerar um índice de produção único que agregue todas as atividades da biblioteca, ou seja, todos os processos e servidos conduzidos na biblioteca relacionados ao atendimento ao cliente e às ações internas.

A família de ações deve ser uma família coerente, ou seja, deve ser coesa, não redundante e exaustiva. A árvore de atividades obtida é apresentada na figura 1 . Os ramos da árvore foram cortados quando não havia diferença de atratividade entre as subações das ações em questão.

$\mathrm{Na}$ segunda fase, ou seja, na fase de avaliação, foi aplicado o método multicritério Macbeth, que se apoiou na modelagem das preferências e na agregação das ações da biblioteca. Essa etapa foi realizada no sentido ramostronco da árvore, ou seja, foi feita uma avaliação para as subatividades e posteriormente para as atividades.

Cabe destacar que a árvore da figura 1 foi construída com base na experiência da bibliotecária da Embrapa Monitoramento por Satélite (decisor) e nas ações realizadas por

FIGURA 1

Árvore de atividades/subatividades da biblioteca da Embrapa Monitoramento por Satélite

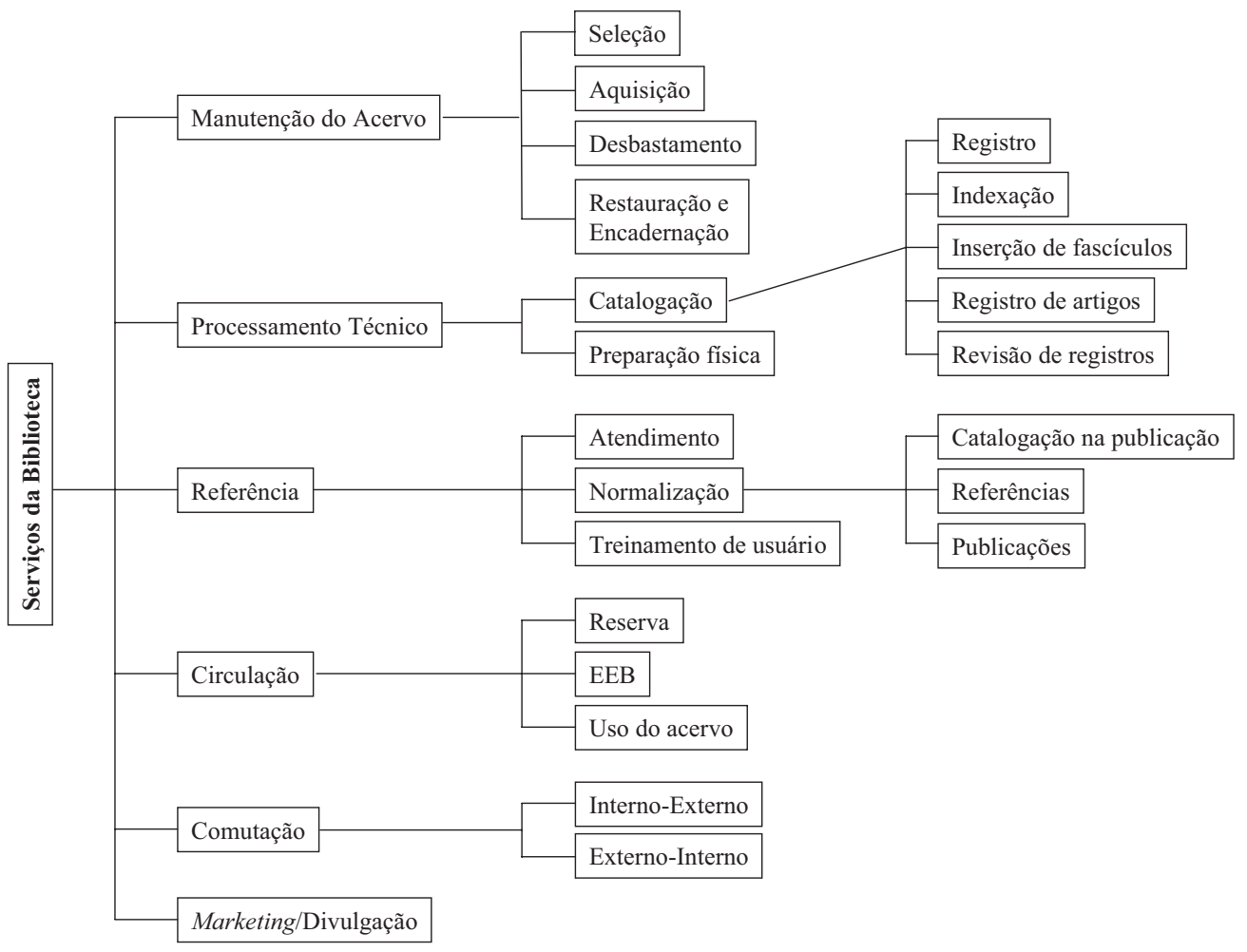


essa biblioteca. Outras bibliotecas podem apresentar árvores de atividades diferentes, e, ao propor uma estrutura única para avaliar todas as bibliotecas de um sistema de bibliotecas, diversos decisores devem ser questionados na tentativa de obter uma "árvore consenso" dessas atividades.

\section{RESULTADOS E DISCUSSÃO}

\section{Avaliação Das subatividades}

\section{Subatividades de "manutenção do acervo"}

A ação de "manutenção do acervo" pode ser dividida em quatro subações de importância diferenciada.

Primeiramente, o método Macbeth pede uma hierarquização por ordem crescente de atratividade desses procedimentos. O decisor propôs a seguinte ordenação: seleção; aquisição; desbastamento; restauração e encadernação.

A segunda etapa é emitir os julgamentos de valor sobre as diferenças de atratividade entre cada par de subatividades da atividade "manutenção do acervo". É construída uma matriz que incorpora os julgamentos. A tabela 1 mostra essa matriz e os julgamentos. Conforme já mencionado, é incluída uma ação fictícia que representa a pior situação dentre todas; nesse caso, por exemplo, seria não executar a atividade de manutenção.

Cada elemento da matriz é preenchido com o julgamento de valor. Por exemplo, o preenchimento do elemento da matriz que avalia a diferença de atratividade entre seleção e atualização é preenchido com a resposta à seguinte pergunta: Dado que, para manutenção do acervo, passar a atividade de seleção do nivel neutro para o nivel bom é mais atrativo que passar a atividade de atualização do nível neutro para o nível bom, qual é essa diferença de atratividade (indiferente, muito fraca, fraca, moderada, forte, muito forte, extrema)?

A pergunta é feita de modo a completar todos os elementos da matriz. Como as ações a avaliar já se encontram em ordem decrescente de atratividade, só é necessário preencher a matriz triangular superior (a outra parte da matriz representaria os julgamentos inversos).

A partir da construção dessa matriz, o método Macbeth é conduzido (resolução dos 4 PPLs seqüenciais) e são gerados os pesos para cada uma das atividades.

Com os julgamentos de valor expressos na tabela 1, os pesos gerados pelo Macbeth para cada ação são os seguintes: seleção $=30,61 \%(\mathrm{SEL})$; aquisição $=30,61 \%$ (AQ); desbastamento $=22,45 \%$ (DESB); restauração e encadernação $=16,33 \%(\operatorname{ReE})$. É ainda facultado ao decisor executar uma análise de sensibilidade que permita alterar os valores dos pesos, dentro dos limites estabelecidos pelos julgamentos de valor e análises de consistência (observe-se que, ao alterar um dos limites, todos os valores de pesos para as demais atividades são alterados, de modo a manter soma igual a 100\%). A tabela 2 apresenta o valor sugerido e os limites superior e inferior para esse caso.

\section{TABELA 1}

Matriz de julgamentos de valor para as subatividades da atividade manutenção do acervo

\begin{tabular}{|l|l|l|l|l|l|} 
& Seleção & Atualização & Desbastamento & $\begin{array}{l}\text { Restauração e } \\
\text { Encadernação }\end{array}$ & $\begin{array}{l}\text { Não manter } \\
\text { o acervo }\end{array}$ \\
\hline Seleção & --- & Indiferente & Forte & Muito forte & Extrema \\
\hline Atualização & --- & --- & Forte & Muito forte & Extrema \\
\hline $\begin{array}{l}\text { Desbastamento } \\
\text { Restauração e }\end{array}$ & --- & --- & --- & & Moderada \\
\hline Encadernação & --- & --- & --- & Extrema \\
\hline Não manter o acervo & --- & --- & --- & --- & --- \\
\hline
\end{tabular}

\section{TABELA 2}

Limites superior, inferior e peso sugerido para os pesos de manutenção do acervo

\begin{tabular}{|l|l|l|l|}
\hline & Limite inferior & Peso sugerido & Limite superior \\
\hline Seleção & 29,81 & 30,61 & 31,35 \\
\hline Aquisição & 29,81 & 30,61 & 31,35 \\
\hline Desbastamento & 17,42 & 22,45 & 23,21 \\
\hline Restauração e Encadernação & 15,49 & 16,33 & 21,13 \\
\hline Não manter o acervo & 0,00 & 0,00 & 0,00
\end{tabular}


Matematicamente, manutenção do acervo pode ser vista como a agregação ponderada aditiva das quatro subatividades, conforme expressão (1).

Manutenção $=30,61 * \operatorname{SEL}+30,61 * \mathrm{AQ}+22,45 * \mathrm{DESB}+16,33 * \mathrm{ReE}$

Subatividades de processamento técnico

Processamento técnico foi dividido nas atividades de catalogação (CAT) e preparação física (PF). Já a catalogação foi ainda dividida em cinco subatividades, já em ordem decrescente de atratividade: registro (REG); indexação (IND); registro de artigo de periódicos (RAP); revisão de registros (RR); inserção de fascículo de periódicos (IFP).

Foi efetuado o mesmo procedimento explicitado anteriormente, de emissão de juízos de valor pelo decisor sobre as diferenças de atratividade entre pares de atividades. Nesse caso, o procedimento foi feito para dois conjuntos: o referente à atividade de catalogação e aquele referente ao processamento técnico.

As tabelas 3 e 4 mostram as matrizes e os julgamentos. As expressões (2) e (3) mostram matematicamente as relações derivadas.

\section{Subatividades referência}

As subatividades de referência são atendimento (ATD), normalização (NORM) e treinamento de usuários (TU), já em ordem decrescente de atratividade. Normalização é ainda subdividido em catalogação na publicação CIP (CIP); referências (REFs); publicações (PUBs) (em ordem decrescente de atratividade).

As tabelas 5 e 6 mostram as matrizes e os julgamentos. As expressões (4) e (5) mostram matematicamente as relações derivadas.

\section{TABELA 3}

Diferenças de atratividade para catalogação

\begin{tabular}{|c|c|c|c|c|c|c|}
\hline & Registro & Indexação & Registro de artigo & $\begin{array}{l}\text { Revisão de } \\
\text { registros }\end{array}$ & $\begin{array}{l}\text { Inserção de } \\
\text { fascículos }\end{array}$ & Não catalogar \\
\hline Registro & --- & Indiferente & Fraca & Forte & Muito forte & Extrema \\
\hline Indexação & --- & --- & Fraca & Forte & Muito forte & Extrema \\
\hline Registro de artigo & --- & --- & --- & Moderada & Muito forte & Extrema \\
\hline Revisão de registros & --- & --- & --- & --- & Muito forte & Extrema \\
\hline $\begin{array}{l}\text { Inserção de } \\
\text { fascículos }\end{array}$ & --- & --- & --- & --- & --- & Extrema \\
\hline Não catalogar & --- & --- & --- & --- & --- & --- \\
\hline
\end{tabular}

\section{TABELA 4}

Diferenças de atratividade para processamento técnico

\begin{tabular}{l|l|l|l}
\multicolumn{2}{c}{ Catalogação } & Preparação física & Não processar \\
\hline Catalogação & --- & Muito forte & Extrema \\
\hline Preparação física & --- & --- & Extrema \\
\hline Não processar & --- & --- & ---
\end{tabular}

$\mathrm{CAT}=23,71 * \mathrm{REG}+23,71 * \mathrm{IND}+21,65 * \mathrm{RAP}+18,56 * \mathrm{RR}=12,37 * \mathrm{IFP}$

(2)

Processamento técnico-66,7*CAT $+33,33 * \mathrm{PF}$

(3)

\section{TABELA 5}

Diferenças de atratividade para a subatividade normalização

\begin{tabular}{l|l|l|l|l}
\multicolumn{2}{c|}{ Catalogação na publicação } & Referências & Publicações & Não normalizar \\
\hline Catalogação na publicação & --- & Moderado & Forte & Extrema \\
\hline Referências & -- & -- & Forte & Extrema \\
\hline Publicações & --- & --- & --- & Extrema \\
\hline Não normalizar & --- & --- & --- & --
\end{tabular}




\section{TABELA 6}

Diferenças de atratividade para a atividade referência

\begin{tabular}{|c|c|c|c|c|}
\hline & Atendimento & Normalização & Treinamento usuário & Não realizar referência \\
\hline Atendimento & --- & Forte & Muito forte & Extrema \\
\hline Normalização & --- & --- & Muito forte & Extrema \\
\hline Não realizar referência & --- & --- & -- & --- \\
\hline
\end{tabular}

$\mathrm{NORM}=42,1 * \mathrm{CIP}+34,21 * \mathrm{REF}+23,68 * \mathrm{PUBs}$

(4)

Referência $=48,15 * \mathrm{ATD}+33,33 * \mathrm{NORM}+18,52 * \mathrm{TU}$

\section{TABELA 7}

Diferenças de atratividade para circulação

\begin{tabular}{l|l|l|l|l}
\multicolumn{2}{l}{ Uso do Acervo } & EEB & Reserva & Não circular \\
\hline Uso do Acervo & --- & Forte & Forte & Extrema \\
\hline EEB & --- & --- & Forte & Forte \\
\hline Reserva & --- & --- & --- & Fraca \\
\hline Não circular & --- & --- & --- & ---
\end{tabular}

Circulação $=55,56 * \mathrm{UA}=33,33 * \mathrm{EEB}+11,11 * \mathrm{RES}$

(6)

\section{TABELA 8}

Diferenças de atratividade para comutação

\begin{tabular}{|l|l|l|l}
\hline \multicolumn{2}{l}{ Interno-Externo } & Externo-Interno & Não fazer comutação \\
\hline Interno-Externo & --- & Forte & Extrema \\
\hline Externo-Interno & --- & --- & Extrema \\
\hline Não fazer comutação & --- & --- & ---
\end{tabular}

Comutação $=62,50 * \mathrm{IE}+37,50 * \mathrm{EI}$

(7)

Subatividades de circulação

Circulação foi dividida nas subatividades de uso do acervo (UA), empréstimo entre bibliotecas (EEB) e reserva (RES), em ordem decrescente de atratividade.

A tabela 7 mostra a matriz e o julgamento de valor sobre as diferenças de atratividade entre as subatividades da atividade circulação, e a expressão (6) traz a formalização matemática desses relacionamentos.

Subatividade de comutação

A atividade de comutação foi dividida nas subatividades de comutação interno-externo (IE) e externo-interno (EI).

A tabela 8 e a expressão 7 resumem os resultados da avaliação destas subatividades.

\section{Avaliação DAS ATIVIDADES}

A etapa de avaliação das atividades é conduzida de maneira análoga às etapas anteriores. Os julgamentos de diferença de atratividade são emitidos (par a par) para as seis atividades identificadas na figura 1 , quais sejam, manutenção do acervo (Manut); processamento técnico (Proctec); referência (Refer); circulação (Circ); comutação (Comut); marketing/divulgação (MKTDV).

Nessa etapa, foi utilizado um procedimento adicional para auxiliar o decisor a estabelecer a ordem decrescente de atratividade. Nessa etapa de ordenação, a pergunta realizada é, por exemplo, a seguinte: Estando as atividades de manutenção do acervo e o processamento técnico ambos no nível neutro, seria mais atrativo passar para o nível bom na atividade de manutenção do acervo ou na de processamento técnico, mantendo-se as outras atividades no nível neutro?

Cada elemento da matriz é preenchido com 0 ou 1 , dependendo da resposta à pergunta: 1 , para o caso de ser atrativa a mudança de nível da ação $X$, e 0 , caso contrário. A ordenação das atividades é feita somandose o valor dos elementos de cada linha; quanto maior o somatório da linha, mais atrativa é a atividade. A tabela 9, a seguir, mostra os resultados para esta etapa. 


\section{TABELA 9}

Ordenação das atividades por atratividade

\begin{tabular}{l|l|l|l|l|l|l|l} 
& MANUT & PROCTEC & REFER & CIRC & COMUT & MKTDV & Soma \\
\hline MANUT & 0 & 1 & 0 & 0 & 0 & 1 & 2 \\
\hline PROCTEC & 0 & 0 & 0 & 0 & 0 & 1 & 1 \\
\hline REFER & 1 & 1 & 0 & 1 & 1 & 5 & 1 \\
\hline CIRC & 1 & 1 & 0 & 0 & 0 & 1 & 1 \\
\hline COMUT & 1 & 1 & 0 & 0 & 0 & 1 & 4 \\
\hline MKTDV & 0 & 0 & 0 & 0 & & 0 &
\end{tabular}

\section{TABELA 10}

Julgamentos de valor sobre as atividades da biblioteca

\begin{tabular}{l|l|l|l|l|l|l|l} 
& REFER & COMUT & COMUT & MANUT & PROCTEC & MKTDV \\
\hline REFER & --- & Forte & Forte & Muito forte & Muito forte & Muito forte & Extrema \\
\hline COMUT & --- & --- & Moderado & Forte & Forte & Muito forte & Extrema \\
\hline CIRC & --- & --- & --- & Moderado & Forte & Muito forte & Extrema \\
\hline MANUT & --- & --- & --- & --- & Moderado & Forte & Extrema \\
\hline PROCTEC & --- & --- & --- & --- & --- & Forte & Extrema \\
\hline MKTDV & --- & --- & --- & --- & Muito forte \\
\hline $\begin{array}{l}\text { Não realizar } \\
\text { atividades }\end{array}$ & --- & --- & --- & --- & -- & - & -
\end{tabular}

Atividades da biblioteca $=22,39 * \mathrm{REFER}+19,90 * \mathrm{COMUT}+18,41 * \mathrm{CIRC}+16,42 * \mathrm{MANUT}+14,43 * \mathrm{PROCTEC}+8,46 * \mathrm{MKTDV}$

(8)

Assim, a ordem de atratividade atribuída pelo decisor às seis atividades é a seguinte: referência (Refer); comutação (Comut); circulação (Circ); manutenção do acervo (Manut); processamento técnico (Proctec); marketing/ divulgação (MKTDV).

A tabela 10 apresenta os julgamentos de valor fornecidos pelo decisor. A expressão (8) mostra a relação matemática entre as atividades realizadas pela biblioteca.

\section{Discussão}

Todas as etapas da metodologia aqui proposta são importantes para os gestores de unidades de informação, pois contribuem para o processo de entendimento da estrutura de atividades realizadas pelas bibliotecas, bem como para a priorização das ações na tomada de decisão.

A visualização das atividades realizadas pela biblioteca em forma de árvore permite uma percepção mais acurada de todas as ações realizadas, bem como de seus relacionamentos. A construção da árvore facilita, ainda, as etapas subseqüentes de ordenação das atividades e de emissão de julgamentos de valor.

A etapa de ordenação permite, a priori, estabelecer uma hierarquização das atividades. Esta etapa pode ser importante aos gestores das unidades de informação nos direcionamentos de prioridades a serem executadas pela biblioteca, já que a atividade ou subatividade de maior atratividade deve receber atenção prioritária.

A metodologia aqui empregada traz a vantagem de não impor ao decisor a indicação direta dos pesos ou importâncias relativas para cada atividade. Ao contrário, ao usar julgamentos pareados qualitativos (expressos por uma escala semântica), facilita a emissão dos juízos de valor por parte do decisor. Ainda, ao indicar inconsistências e permitir análises de sensibilidade, insere de maneira ativa o decisor no processo de determinação dos pesos. Encontram-se na literatura métodos análogos, como o AHP (SAATY, 1980), com vantagens e desvantagens comparativas ao Macbeth (COSTA; VANSNICK, 2001).

A obtenção dos pesos tem importantes finalidades para as unidades de informação: expressar a importância relativa de cada atividade/subatividade na atividade global das bibliotecas e permitir a construção de um índice ponderado de produção, que pode expressar com maior fidelidade a produção (ou a produtividade, se for o caso) de cada biblioteca. Por exemplo, considere-se produção das duas bibliotecas mostradas na tabela 11. Ambas apresentam o mesmo valor "global" de produção, se não forem 
TABELA 11

Exemplo numérico

\begin{tabular}{l|l|l} 
Atividades & Biblioteca A & Biblioteca B \\
\hline Referência & 15 & 10 \\
\hline Comutação & 20 & 10 \\
\hline Circulação & 5 & 5 \\
\hline Manutenção do acervo & 30 & 15 \\
\hline Processamento técnico & 25 & 20 \\
\hline Marketing/Divulgação & 5 & 40 \\
\hline Índice de produção simples * & 100 & 100 \\
\hline Índice de produção ponderado ** & 17,2 & 13,9
\end{tabular}

* Soma da produção de cada atividade.

** Soma ponderada considerando a expressão (8)

consideradas as diferenças de atratividade entre as ações conduzidas. Entretanto, caso se considere que os pesos aqui propostos, que expressam "graus de importância", são válidos para ambas as bibliotecas, a biblioteca $\mathrm{A}$ deve ser considerada como a que produziu mais.

\section{CONCLUSÕES}

Este artigo traz uma primeira aproximação para o estudo da importância relativa de processos e serviços realizados por bibliotecas, com o uso de modelos de pesquisa operacional, a saber, modelos do apoio multicritério à decisão, com o objetivo de gerar um índice de produção ponderado de atividades de bibliotecas.

Essa metodologia mostrou-se bastante útil e adequada para a avaliação de atividades de bibliotecas. Tanto a etapa de estruturação do problema, com a eleição das atividades e subatividades, quanto a emissão de juízos de valor dependem da interação com o decisor. Cabe ressaltar que a árvore de atividades poderia ser dividida em dois ramos principais: serviços ao cliente (compreendendo os ramos referência, circulação, comutação e marketing/ divulgação) e serviços/processos internos (manutenção do acervo e processamento técnico), que podem ter

\section{REFERÊNCIAS}

BUCKLAND, M. Library services in theory and context. 2. ed. [S.l.]: Michael Buckland, 1999.

Redesigning library services: a manifesto. [S.l.]: American

Library Association, 1992.

COSTA, C. A. Bana e; CHAGAS, M. P. A career choice problem: an example of how to use Macbeth to build a quantitative value model based on qualitative value judgments. European journal of operational research, v. 153, n. 2, p. 323-331, 2004.

; FERREIRA, J. A. A; CORREA, E. C. Metodologia multicritério de apoio à avaliação de propostas em concursos públicos. importâncias diferenciadas dependendo do objetivo principal da biblioteca.

Os pesos, além de serem usados quantitativamente na composição do índice de produção, podem ser usados como ferramentas de apoio à gestão de unidades de informação, já que pesos mais elevados significam maior importância relativa da atividade, que deve ser priorizada quando há conflitos na sua gestão. Conforme já destacado, este é um estudo-piloto que fez uso dos julgamentos de um único decisor. Decisores diferentes podem gerar famílias de critérios e importâncias relativas diferentes.

Finalmente, o índice proposto pode servir como medida de comparação de produção de atividades entre diversas bibliotecas, em especial quando estão sujeitas a uma administração central, que necessita de resultados objetivos para apoiar suas decisões e como ferramenta de planejamento estratégico. Nesse caso, o estudo deve ser conduzido considerando-se a opinião de outros agentes de decisão, de modo que o índice represente a realidade do sistema de bibliotecas, e não de uma biblioteca específica.

Artigo recebido em 14/10/2004 e aceito para publicação em 15/08/2005.

In: ANTUNES, C. H.; TAVARES, L.V. (Ed.). Casos de aplicação da investigação operacional. Amadora: McGraw Hill, 2000, p. 336-363.

; VANSNICK, J. C. A fundamental criticism to Saaty's use of the eigenvalue procedure to derive priorities. London: London School of Economics, 2001. Working Paper LSEOR 01.42.

. Thoughts on a theoretical framework for measuring attractiveness by categorical based evaluation technique (MACBETH). In: CLÍMACO, J. (Ed.) Multicriteria analysis. Berlin: Springer-Verlag, 1997.

. Uma nova abordagem ao problema da construção de uma função de valor cardinal: Macbeth. Investigação operacional, v. 15, p. 15 35, 1995. 


\section{Eliane Gomes / Maria de Cléofas Alencar}

DIAS, L. M. C.; ALMEIDA, L. M. A. T.; CLÍMACO, J. Apoio multicritério à decisão. Coimbra: Universidade de Coimbra, 1996.

GOMES, E. G. Integração entre sistemas de informação geográfica e métodos multicritério no apoio à decisão espacial. 1999. Tese (Mestrado em Engenharia de Produção)- COPPE, Universidade Federal do Rio de Janeiro, Rio de Janeiro, 1999.

GOMES, L. F. A. M.; GOMES, C. F. S.; ALMEIDA, A. T. Tomada de decisão gerencial: enfoque multicritério. São Paulo: Editora Atlas, 2002.

; GONZALEZ-ARAYA, M. C.; CARIGNANO, C. Tomada

de decisões em cenários complexos. São Paulo: Pioneira Thompson Learning, 2004.

MELLO, J. C. C. B. Soares de et al. Conceitos básicos do apoio multicritério à decisão e sua aplicação no projeto aerodesign. Engevista, v. 5, n. 8, p. 22-35, 2003.

MUELLER, S. P. M.; PECEGUEIRO, C. M. P. de A. O periódico Ciência da Informação na década de 90: um retrato da área refletido em seus artigos. Ciência da informação, Brasília, v. 30, n. 2, p. 47-63, 2001.
POMEROL, J. C.; BARBA-ROMERO, S. Multicriterion decision in management: principles and practice. Boston: Kluwer Academic Publishers, 2000.

ROY, B.; BOUYSSOU, D. Aide multicritère à la décision: méthods et cas. Paris: Economica, 1993.

SAATY, T. L. The analytic hierarchy process. New York: McGraw Hill Company, 1980.

SANTOS, L. C.; FACHIN, G. R. B.; VARVAKIS, G. Gerenciando processos de serviços em bibliotecas. Ciência da Informação, Brasília, v. 32, n. 2, p. 85-95, 2003.

STUBBS, E. A. Indicadores de desempeño: natureza, utilidad y construcción. Ciência da Informação, Brasília, v. 33, n. 1, p. 149-154, 2004.

YU, P. L. Multiple criteria decision making: concepts, techniques and extensions. New York: Plenum Press, 1985. 